\title{
Insulin Pump Termination in Adult Patients
}

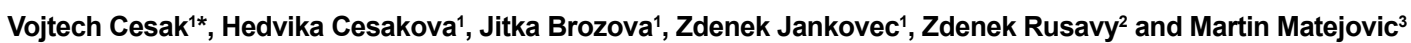

${ }^{1}$ Ist Medical Department, University Hospital Pilsen, Czech Republic

${ }^{2}$ Head of the Metabolic Group, Ist Medical Department, University Hospital, Pilsen, Czech Republic

${ }^{3}$ Head of the Ist Medical Department, University Hospital, Pilsen, Czech Republic

\begin{abstract}
Introduction: Insulin pump therapy presents an increasingly used method. Its usage has been steadily increasing within last 40 years and number of studies concerning the insulin pump therapy commencement and various aspects arising in course of the treatment, was presented. But only few studies dealing with the patients after insulin pump treatment termination exist. Furthermore, the majority of these studies are focused on pediatric population. Objectives: to determine, whether the glycemic control changes after insulin pump termination regardless of the type of diabetes or method of treatment withdrawn (pump withdrawn by a physician vs. patient's wish). To evaluate whether the glycemic control after insulin pump termination differs in type 1 and type 2 diabetic patients and if there are any changes after insulin pump termination due to the method of treatment withdrawn (pump withdrawn by a physician vs. patient's wish)

Methods: The CSII treatment was terminated to a total of 228 patients in 2001 - 2012. 74 patients had sufficient data to analyze four variables: $\mathrm{HbA} 1 \mathrm{c}$, weight, total daily bolus insulin dose, and total daily basal insulin dose. The initial values was derived from data 3-6 months before the treatment withdrawal, other data were collected at time of withdrawal, and at 3, 6, 12 and 24 months following the CSII treatment termination. Total length of follow-up was 2.5 years.

Results: There was no significant change in $\mathrm{HbA1c}$ : it was $78.5 \mathrm{mmol} / \mathrm{mol}$ (interquartil range 69 ; 95) at time of insulin pump treatment (specifically in the last half year prior to treatment withdrawal) and $81 \mathrm{mmol} / \mathrm{mol}(68 ; 93)$ at time of treatment termination $(\mathrm{p}=0,365)$. The median of weight was $81 \mathrm{~kg}$ (interquartil range $67 ; 95) 3-6$ months prior to treatment termination and $80 \mathrm{~kg}$ (interquartil range 66,$8 ; 97$ ) at time of withdrawal. These changes are also nonsignificant $(p=0,963)$. The only significant change observed was the increase in the total daily bolus insulin dose after the treatment termination - median at time of termination $20 \mathrm{IU} /$ day and after withdrawal $30 \mathrm{IU} /$ day $(p=0,001)$. The dose of basal insulin was not significant $(p=0,619)$. The evaluation of subgroups (type 1 diabetes versus type 2 diabetes and pump withdrawn by a physician versus patient's wish group) was the same results - e.g. the only significant change was in the dose of bolus insulin.
\end{abstract}

Conclusions: In our study, we were not able to demonstrate any impact of insulin pump treatment termination on the further development of glycemic control of the patients.

Keywords: Diabetes mellitus; Insulin pump; Termination; Glycemic control; Type 1 diabetes; Type 2 diabetes

\section{Introduction}

Diabetes mellitus is currently a very important medico-social problem. It is expected that by the year 2030 there will be around 550 million diabetic patients in the world. The first written evidence of the disease was documented more than 3,500 years ago. With the gradual development of medicine, pancreas was being associated with diabetes mellitus and after the discovery the islets of Langerhans and subsequently insulin, the nature of the disease was determined. The treatment of diabetes was almost impossible until in the middle of the 20th century, when in 1921, Frederick Banting isolated insulin from canine pancreas. Ever since, the treatment of diabetes mellitus changed dramatically and constant advances in treatment persist until today. Syringes for insulin administration were replaced by insulin pens and subsequently by the most modern way of current treatment - insulin pump. It is basically a specific modality of multiple daily injections treatment, which pursues imitation of physiological insulin secretion. Since the 70ties, when John Pickup published his first experience, the insulin pump treatment developed considerably and at present it constitutes an increasingly used method. Its usage has been steadily increasing within last 40 years - while in 2002 around 180,000-200,000 diabetic patients were treated by an insulin pump [1], in 2005 they were about 400,000 and at present it is estimated that insulin pump is used by approximately 750,000 up to a million of diabetic patients in the world. The extent of its use naturally differs in individual countries (the highest in the USA, Israel and Switzerland).

\section{Advantages and disadvantages of CSII treatment}

The amount of studies concerning this specific treatment has been growing with the increasing number of patients with CSII treatment. The treatment was studied from various points of view and gradually, numerous advantages and disadvantages both for physicians and patients were revealed.

Probably the most important observed variable is the efficacy of the insulin pump treatment in comparison with multiple daily injections

${ }^{*}$ Corresponding author: Vojtech Cesak, M.D, Ist Medical Department, University Hospital Pilsen, Czech Republic, Tel: +420 377103 512; E-mail: cesakv@fnplzen.cz

Received August 10, 2015; Accepted September 14, 2015; Published September 19,2015

Citation: Cesak V, Cesakova H, Brozova J, Jankovec Z, Rusavy Z, et al. (2015) Insulin Pump Termination in Adult Patients. J Diabetes Metab 6: 606 doi:10.4172/2155-6156.1000606

Copyright: @ 2015 Cesak V, et al. This is an open-access article distributed unde the terms of the Creative Commons Attribution License, which permits unrestricted use, distribution, and reproduction in any medium, provided the original author and source are credited. 
and the influence of CSII teratment on chronic comlications of diabetes. It is well known that serious microvascular complications of diabetes are linked to the duration and severity of hyperglycemia. In general poor glycemic control and variability in $\mathrm{HbAlc}$ in addition to duration of diabetes is closely linked to the development of complications [2]. Except of hyperglycemia there are some other factors related to the development of diabetic complications (microvascular and also macrovascular) in type 1 diabetes mellitus (modifiable - hypertension, dyslipidaemia, diet, smoking, etc. and non-modifiable - age, genes) [3]. Several large studies clearly demonstrated the improvement in glycemic control, expressed by HbAlc reduction, in a long-term follow-up on a large sample of adult diabetic type 1 patients treated with insulin pump [4-6]. In the Diabetes Control and Complications Trial (DCCT) was demonstrated that the intensive blood glucose control treatment reduces the risk of microvascular complications (diabetic retinopathy, diabetic kidney disease or nephropathy and diabetic neuropathy). Patients with type 1 diabetes have also an increased risk of developing macrovascular complications, especially cardiovascular disease, relative to the nondiabetic population. The premature atherosclerosis represents the main cause of morbidity and mortality in patients with type 1 diabetes mellitus [7]. In EDIC study, the risk for any cardiovascular disease event was much lower in group treated intensively. EDIC study clearly showed that cardiovascular disease could be reduced significantly and independently by intensive glycemic control. Then other following trials showed the same $[8,9]$. CSII in type 1 diabetes is associated with a reduction in severe hypoglycemia and reduction $\mathrm{HbAlc}$ and it should be an appropriate treatment option for adults and children $\geq 12$ years of age with type 1 diabetes when attempts to achieve target HbAlc levels with multiple daily injections have resulted in disabling hypoglycemia or when $\mathrm{HbAlc}$ have remained high [10].

The current meta-analysis of 41 randomized and observational studies clearly confirms the abovementioned improvement in the glycemic control in diabetic type 1 patients treated by insulin pump but there was no statistically significant effect on the quality of life or incidence of severe hypoglycemic episodes. In adult type 2 diabetic patients and pregnant women no significant influence on the incidence of hypoglycemic episodes, quality of life measures and even glycemic control was found [11].

We cannot abide by statistics alone; an individual approach in selection of suitable patients is necessary. A certain promise of better glycemic control could be brought by wider use of the continuous blood glucose monitoring [11].

Among the disadvantages belongs undoubtedly the economic aspect of the treatment, which is several times more demanding than that of multiple daily injections [12,13]. At present, no ideal system for financing of the health care exists in the world and we should therefore select the patients suitable for CSII treatment carefully. The insulin pump treatment cost is in the range of $\$ 5,000-7,000$ for the device (depending on the manufacturer and country) and every year of operation costs around $\$ 2,500$ (costs of insulin, infusion sets, cannulas, batteries).

The cost per quality-adjusted life year (QALY) gained per 1-year period ranges approximately from $\$ 25,000$ to $\$ 55,000$ per year of gained life, which is a limit of potentially beneficial treatment [14]. The basic principle for the improvement of the economic aspect of CSII treatment is the individual approach, selection of suitable patients, frequent assessment of treatment efficacy and lack of concern about continuity disruption (not hesitate to terminate the treatment if ineffective). The benefit of upgrading the treatment by sensors is also disputable; glycemic control improvement was demonstrated clinically $[11,15]$, however, the costs of a treatment that could have been a standard by now are currently too high [16].

Regarding local treatment complications, mainly skin changes like lipoatrophy, lipohypertrophy, allergic reactions (to insulin or inserted cannula), or local inflammations (phlegmons or abscesses) were observed. The local inflammations are probably the most common complication of CSII treatment $[17,18]$ and constitute also a problem that can lead to CSII treatment termination [19]. The incidence of local infections is higher in CSII compared with multiple daily injections [20]. Prevention is very important here; regular change of the infusion set every 2-3 days, hygiene habits as washing the skin prior to another set insertion, or use of antiseptics minimize the risk of the infection. If the infection occurs, the most common pathogens are staphylococci or streptococci [21]. Usually they are smaller local affections, rarely extensive infections such as cellulitis or abscesses requiring surgical intervention develop [21].

The risk of diabetic ketoacidosis development in diabetic patients treated with CSII is controversial. The main cause is the small depot of subcutaneous insulin. The subcutaneous insulin reserve gets rapidly depleted upon suspension of the delivery and ketoacidosis may develop rather quickly then. In multiple daily injections the development is slower due to the presence of the basal insulin [20]. According to some physician's opinions, this is an important adverse effect of CSII treatment [22]. There seems to be an increased risk for ketoacidosis in pump users when pumps are used primarily to improve metabolic control in patients with not so low an HbAlc. On the other hand, the incidence of ketoacidoses is decreasing with increasing experience of the doctors and patients alike. For patients with good compliance and adequate family support (especially in pediatric population), the risk of DKA seems lower. The question about ketoacidosis is still open and a number of studies that were unable to find a statistically significant difference in the diabetic ketoacidosis incidence when comparing insulin pump and multiple daily injections exist [23].

No data regarding the failure rate and reliability of the insulin pumps exist. This data is probably available only in databases of individual manufacturers.

The view of the patient is also important. The permanently inserted cannula represents a benefit against multiple daily injections. It eliminates repeated insulin administration, which may induce pain and thus reluctance to bolus administration before meals as well as e.g. correction boluses. The possible error in administration is minimized, as with the growing number of administrations the risk of negligent insulin application or its administration in lipodystrophy leading to significant variability in the amount of absorbed insulin increases. Another advantage for the patients is the higher flexibility of their lifestyles. Basal insulin is to certain extent non-flexible, it is difficult to set the regimen in sports-active individuals, but also e.g. in case dawn phenomenon. A certain disadvantage can be the fact that the patient must have the device on him at all times, furthermore, certain degree of technical skill and motivation to cooperate (not by motto: "The pump will treat the diabetes for me") and sufficient level of knowledge of their disease (e.g. knowledge of the saccharide content of the foodstuffs, at least basic principles of insulin therapy correction, etc.) are required.

Naturally there are situations when we have the right to terminate the insulin pump treatment:

I) The glycemic control worsens in the course of the treatment 
II) Frequent complications at the cannula insertion site or other technical complications are present.

III) Insufficient cooperation of the patient (few measurements, repeated pump suspension, not attending regular appointments, ...)

\section{IV) Patient's wish}

In our Diabetes center at the University Hospital Pilsen we never terminate insulin pump treatment in patients with dawn phenomenon and in patients with reduction in the number of severe hypoglycemias in the course of the treatment. The insulin pump treatment is reevaluated in all patients every 4 years.

Overall we can say that in comparison with the number of studies concerning the insulin pump therapy commencement and various aspects arising in course of the treatment, only few studies dealing with the patients after insulin pump treatment termination exist. Furthermore, the majority of these studies are focused on pediatric population [24,25]. The very lack of knowledge regarding further development of glycemic control following insulin pump termination in adult diabetic patients was the motivation for our retrospective observational study.

\section{Objectives}

The primary objective of our study was to determine, whether the glycemic control changes after insulin pump termination regardless of the type of diabetes or method of treatment withdrawn (pump withdrawn by a physician vs. patient's wish). The secondary objective was to evaluate whether the glycemic control after insulin pump termination differs in type 1 and type 2 diabetic patients. Another secondary aim was the answer to the question if the glycemic control changes after insulin pump termination due to the method of treatment withdrawn (pump withdrawn by a physician vs. patient's wish).

\section{Methods}

Patients: National register of patients treated with insulin pump in the Czech Republic managed by our Diabetes Center was used for data acquisition. The CSII treatment was terminated to a total of 228 patients in 2001-2012. We had only one inclusion criterion - the sufficient data for statistical analysis to regard the primary objective, irrespective of the type of diabetes or length of treatment by insulin pump. This condition fulfilled 74 patients (we remember the sample size is very less and we want to make the update of data after few years). The exclusion criteria were the lack of data to evaluate. All of the patients, who were willing to participate the trial, signed the patient's consent to provide their data (anonymously) for statistical analysis and publishing. The consents were signed during regular controls in our diabetes center or patients received it by post.

\section{Evaluation}

Total length of follow-up was 2.5 years. The initial values was derived from data 3-6 months before the treatment withdrawal, other data were collected at time of withdrawal, and at 3, 6, 12 and 24 months following the CSII treatment termination. Four variables were evaluated: HbAlc, weight, total daily bolus insulin dose (before insulin pump termination as total daily dose of insulin applied boluses, after insulin pump termination boluses in multiple daily injections) and total basal insulin dose (before insulin pump termination as total daily dose of insulin applied basal, after insulin pump termination total dose of basal insulin in multiple daily injections). Subsequently, the data was sorted according to the type of diabetes and method of treatment termination. Two main reasons for treatment withdrawal could be observed in the enrolled patients - insulin pump termination from the decision of a physician in 51 patients and patient's own wish in the remaining 23 patients. The effect of CSII termination on the glycemic control was observed in each group separately, and also between the two groups. The analysis of the data with respect to the type of diabetes was performed in an analogous way. In total, 44 patients with type 1 diabetes and 30 patients with type 2 diabetes were enrolled.

\section{Statistical evaluation}

For statistical analysis we used statistical software. We used the nonparametric Friedman test for comparing differences between groups (in our case for continuous data) and the Wilcoxon non-parametric statistical hypothesis test (paired difference test) to compare related samples (in our case pairs of data before and after CSII termination in our groups and subgroups).

\section{Results}

In our retrospective observational study we worked with a group of 74 patients ( 32 men, 42 women), both with type 1 and 2 diabetes mellitus (type 1 diabetes in 44 patients, i.e. $59.5 \%$ and type 2 diabetes in 30 patients, i.e. $40.5 \%$ ), in whom the insulin pump treatment was terminated in the period of 2001-2012. The age of the patients was 52 years (interquartil range $32.25 ; 63$ ), mean diabetes duration at time of insulin pump termination was 18.4 years $(S D \pm 9.5)$ and mean length of insulin pump treatment was 4.2 years $(\mathrm{SD} \pm 4$ ). The $\mathrm{HbA} 1 \mathrm{c}$ was 78.5 $\mathrm{mmol} / \mathrm{mol}$ (interquartil range $69 ; 95$ ) at time of insulin pump treatment (specifically in the last half year prior to treatment withdrawal) and 81 $\mathrm{mmol} / \mathrm{mol}(68 ; 93)$ at time of treatment termination. This change is not statistically significant $(\mathrm{p}=0,365)$. Regarding the body weight, the median weight was $81 \mathrm{~kg}$ (interquartil range 67; 95) 3-6 months prior to treatment termination and $80 \mathrm{~kg}$ (interquartil range $66.8 ; 97$ ) at time of withdrawal. Again no statistically significant changes $(\mathrm{p}=0,963)$.

Insulin pump treatment was terminated for two main reasons: patient's wish or physician's recommendation. The reasons for treatment termination by the physician were long-term poor glycemic control with $\mathrm{HbAlc}$ over $80 \mathrm{mmol} / \mathrm{mol}$ with a trend towards further deterioration in the last half year prior to the pump termination (31 patients), insufficient compliance in the treatment (low number of measurements, repeated insulin delivery suspension) ( 7 patients), longterm trend towards weight gain (4 patients), repeated hypoglycemias in course of insulin pump treatment (4 patients), long-term ineffective insulin pump treatment ( 3 patients), local complication with inserted cannula ( 1 patients) and pump destruction due to maltreatment (1 patient). Reasons why patients themselves wished the insulin pump treatment termination were the following; mental intolerance (8 patients), long-term poor glycemic control in the course of insulin pump treatment (5 patients), local complications from inserted cannula (4 patients), inability of operation medically (3 patients), inability of operation technically ( 2 patients) and intolerance of the pump during physical activity (1 patient).

The length of follow-up after the insulin pump treatment termination was 2 years. Upon comparison of HbAlc levels prior to insulin pump treatment termination (median $78.5 \mathrm{mmol} / \mathrm{mol}$, interquartil range 69 ; 95) with other values following the withdrawal, we were unable to find any statistically significant differences. The same results were obtained in case of analogous comparison of body weight $(p=0,963)$ and total basal insulin dose $(p=0,619)$. The only significant change observed was the increase in the total daily bolus insulin dose after the treatment termination $(p=0,001)$ - median at time 
of termination $20 \mathrm{IU} /$ day and after withdrawal $30 \mathrm{IU} /$ day. On the one hand, it is must be said that purely from a statistical point of view, it is a different variable - instead of one type of insulin (human insulins used in CSII - insulin lispro or isulin aspart), suddenly more insulin types are used in multiple daily injections (human insulins, insulin analogs, insulins contained in premixed preparations). On the other hand, we have two explanations for the increase. It is a known fact that after insulin pump treatment commencement, the insulin doses are reduced by approximately $1 / 2-1 / 3$, which is probably related to the amount of insulin in the subcutaneous depot and its absorption. Analogously, insulin pump termination leads to an increase in total insulin requirement. Another possible explanation is the unsuitable bolus to basal ratio during the insulin pump treatment. It is acknowledged that the bolus to basal ratio should ideally be approx. 50:50 or 60:40 in favor of bolus doses. In our case the ratio was inversed (43:57 at 3-6 months prior to the withdrawal, $42: 58$ at time of the termination). When setting the new regimen, ideal ratio enabling higher flexibility was set (50:50 at 3 months from the termination) and the requirement for the shortacting insulin thus increased.

When we compared the $\mathrm{HbAlc}$ value at time of the termination (median $81 \mathrm{mmol} / \mathrm{mol}$, interquartil range 68 ; 93) with all other values onwards, we were not able to find any statistically significant differences (Figure 1). No statistical significance was found for variables like body weight and total insulin dose administered as basal either. Again, the abovementioned significant increase in the bolus insulin dose was found.

Therefore, when we considered the group of all 74 patients as a whole (regardless of the method of treatment termination or diabetes type), then in our retrospective observational study no statistically significant differences in the change of variables like $\mathrm{HbAlc}$, body weight and total insulin dose administrated as basal were found in the course of 2 years following the insulin pump treatment termination. The increase in insulin administered as bolus was statistically significant. The glycemic control thus was not fundamentally affected.

Evaluation of individual subgroups in time regarding method of insulin pump treatment termination (physician's recommendation and patient's wish) and regarding the type of diabetes (type 1 and type 2) we proceeded in an analogous way (i.e. comparison of individual variables prior to the termination with others after the withdrawal, then at time of withdrawal with other variables following the termination, and a possible significant change throughout the whole time period). Again no statistically significant differences in variables like body weight and HbA1c (Table 1), and also total insulin dose administered as basal could be found. As well as in the previous cases, an increase in the total daily bolus insulin dose administered as bolus was present (Figures 2 and 3).

It can thus be concluded that the type of diabetes nor the method of termination do not influence the glycemic control following the insulin pump treatment termination.

A multivariate analysis of the outcome following insulin pump treatment termination regarding the reasons of termination and type of diabetes would yield no statistically significant differences in the observed variables.

\section{Discussion}

In our retrospective observational study we assessed the influence of the insulin pump treatment termination on the glycemic control. 74

\section{HbA1c}

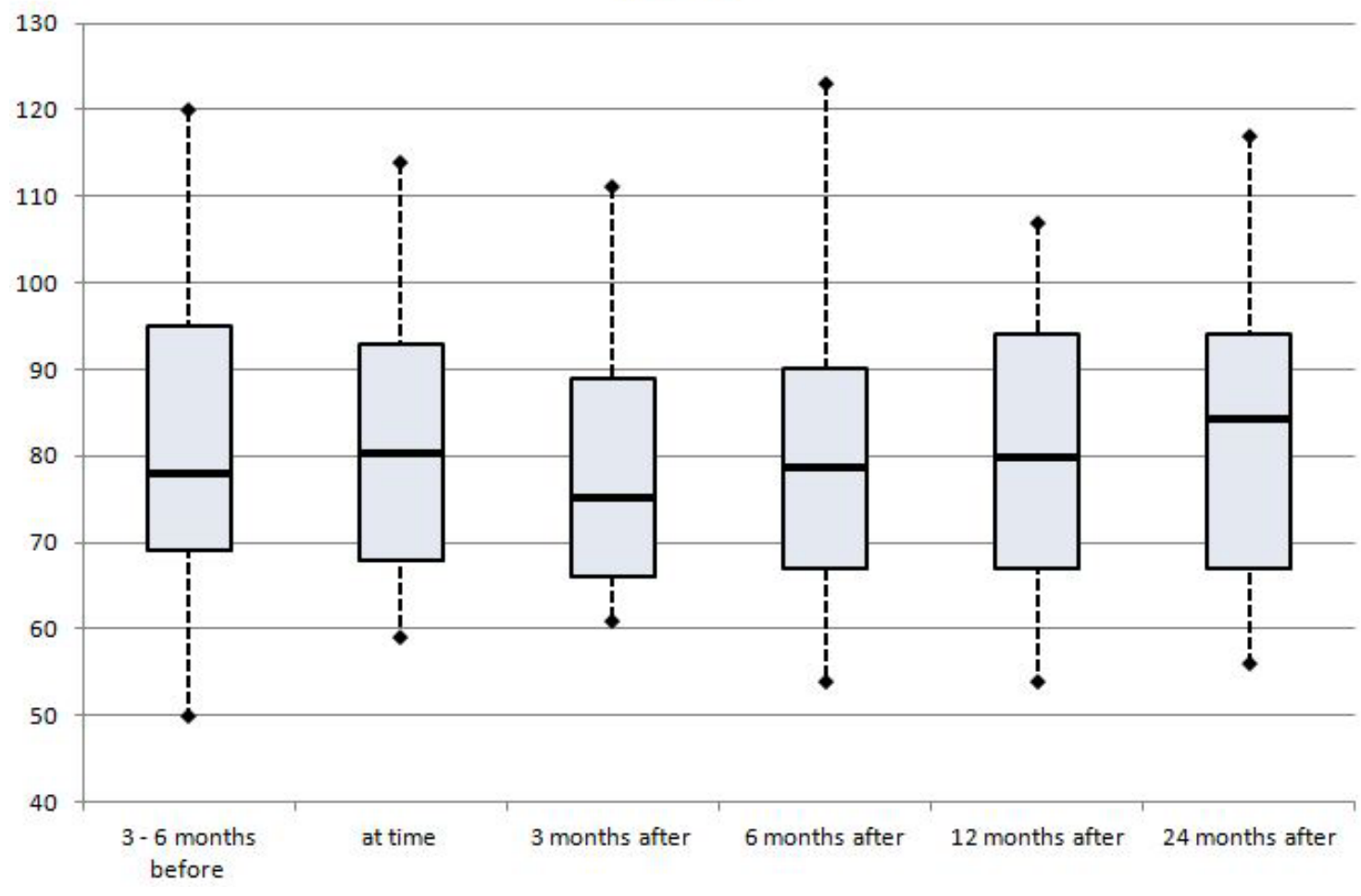

Figure 1: $\mathrm{HbA1}$ c regardless of the method of treatment termination or diabetes type. 
Citation: Cesak V, Cesakova H, Brozova J, Jankovec Z, Rusavy Z, et al. (2015) Insulin Pump Termination in Adult Patients. J Diabetes Metab 6: 606. doi:10.4172/2155-6156.1000606

Page 5 of 7

\begin{tabular}{|c|c|c|c|c|c|c|c|c|}
\hline Group & Parameter & $\begin{array}{l}\text { 3-6 months } \\
\text { before } \\
\text { discont. }\end{array}$ & $\begin{array}{l}\text { At the time of } \\
\text { discont. }\end{array}$ & $\begin{array}{c}3 \text { months } \\
\text { after discont. }\end{array}$ & $\begin{array}{l}6 \text { months after } \\
\text { discont. }\end{array}$ & $\begin{array}{l}12 \text { months after } \\
\text { discont. }\end{array}$ & $\begin{array}{l}24 \text { months after } \\
\text { discont. }\end{array}$ & $\mathbf{p}$ \\
\hline \multirow{2}{*}{ Discont. CSII- patient's wish } & $\mathrm{HbA1c}$ & 68 & 71 & 73 & 73 & 72 & 67 & 0.941 \\
\hline & Weight & 76 & 76 & 77 & 77 & 77 & 78 & 0.223 \\
\hline \multirow{2}{*}{ Withdrawn CSII by a physician } & $\mathrm{HbA1c}$ & 83 & 83 & 76 & 78 & 80 & 81 & 0.810 \\
\hline & Weight & 80 & 80 & 79 & 81 & 81 & 81 & 0.426 \\
\hline \multirow{2}{*}{ Type 1 diabetes } & $\mathrm{HbA1c}$ & 83 & 85 & 82 & 78 & 80 & 81 & 0.860 \\
\hline & Weight & 68 & 67.5 & 70.5 & 70 & 72 & 73 & 0.432 \\
\hline \multirow{2}{*}{ Type 2 diabetes } & $\mathrm{HbA1c}$ & 71 & 73.5 & 72 & 70.5 & 70.5 & 74 & 0.580 \\
\hline & Weight & 87.6 & 87.9 & 88 & 88 & 89.5 & 88 & 0.759 \\
\hline
\end{tabular}

Table 1: HbA1c and weight subgroups.

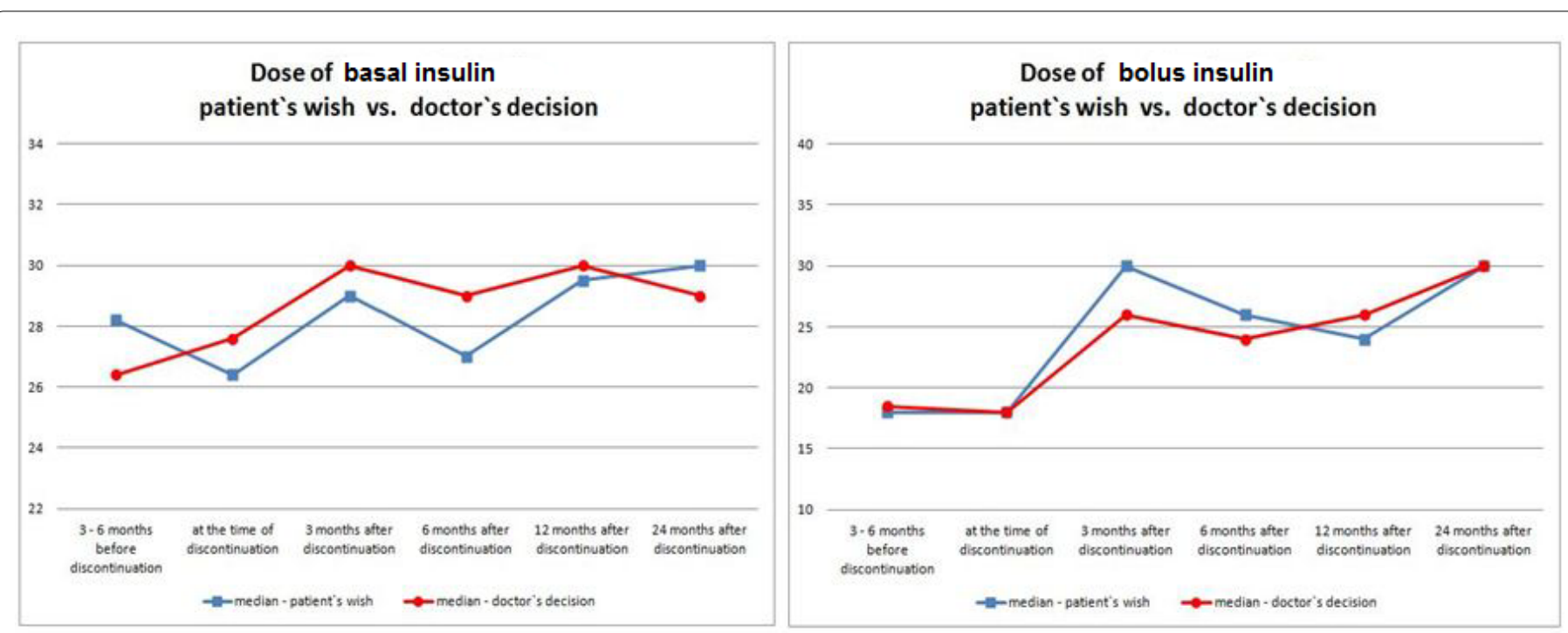

Figure 2: Total daily basal insulin dose and total daily bolus insulin dose due to the method of treatment termination.
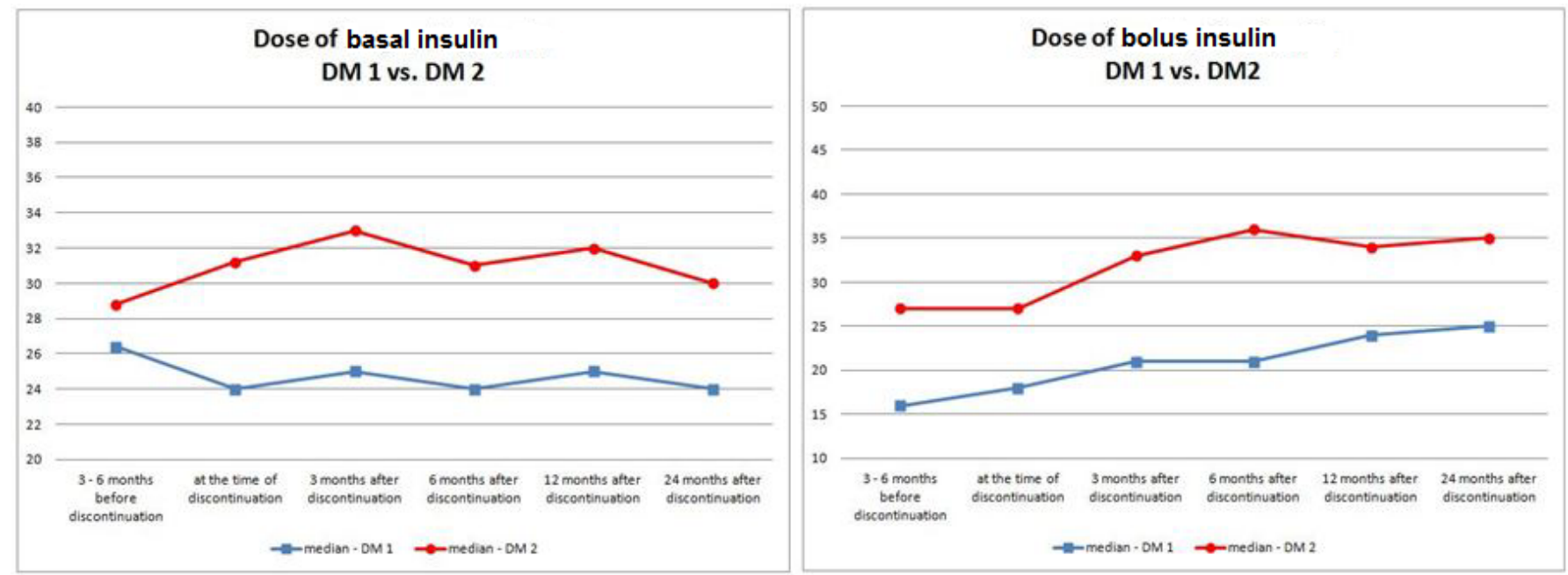

Figure 3: Total daily basal insulin dose and total daily bolus insulin dose due to the type of diabetes.

of total 228 patients, to whom their insulin pump was withdrawn for various reasons in a period of 2001-2012, were enrolled in the study. The majority of patients could not be enrolled for several reasons, where the cardinal reason was the lack of data for evaluation (patients did not attend checks, were referred to a physician outside the University
Hospital Pilsen for further follow-up, insulin pump was withdrawn recently, deaths, etc.).

From a number of studies we know that insulin pump treatment commencement in diabetic type 1 patients leads to glycemic control improvement, while in type 2 diabetes the effect is not unequivocal. The 
effect of its termination on glycemic control in adults is ambiguous as well. At present, only few studies dealing with insulin pump termination exist and these are usually focused on pediatric population. De Vries in his study from 2011 dealt with the problem, whether certain risk factors for insulin pump treatment failure prediction could be determined. Within eight retrospectively evaluated years the pump was withdrawn to 48 patients. The evaluation identified two statistically significant variables associated with insulin pump treatment failure, i.e. female gender at the age over 10 years and high $\mathrm{HbAlc}$ at time of insulin pump commencement $(86 \pm 12,7 \mathrm{mmol} / \mathrm{mol})$. Our data show no observable influence of gender or age. While in De Vriese's study $75 \%$ of all patients with withdrawn insulin pump treatment were women, in our study the proportion of men and women was more even (57\% women, $43 \%$ men). Regarding the age, no difference in the age distribution at time of insulin pump treatment commencement was observed (men median age 50 years $(31 ; 58.25)$, women median age 45 years $(31,5 ; 61)$ ). Among children above 10 years of age, it can be assumed that the main reason for the treatment failure is the emerging puberty and certain act of resistance. The interest in other activities with a specific denial of the presence of diabetes is also reflected in the proven deterioration of the glycemic control after the pump withdrawal. We cannot precisely comment on $\mathrm{HbAlc}$, due to the lack of complete data from individual patients from the time period before start of insulin pump. However, no deterioration in $\mathrm{HbAlc}$ in comparison with entry value before insulin pump commencement and it's termination was found. Among other discussed factors belong severe hypoglycemia incidence and frequency of diabetic ketoacidosis, which were not proven to be a significant risk factor. These factors were not found significant in our adult population and due to this they were not evaluated. It is therefore evident that some risk factors that could predict insulin pump treatment failure observed in children, do not apply for adults (more precisely in our study) and others cannot be commented on due to the absence of data.

Regarding the reasons for insulin pump treatment termination, mainly deterioration in glycemic control was presented (including repeated episodes of ketoacidosis, HbAlc increase, but also noncompliance - omitting boluses, etc.), mental problems (maladjustment to the pump), technical inability of pump operation and finally cases when the pump interfered with everyday life (e.g. in dancers). In our study, if we conserved this classification of the reasons for pump withdrawal, the distribution among the groups is identical. The largest proportion is constituted by the group with gradual deterioration of glycemic control or noncompliant patients, then mental intolerance. The smallest groups are of patients with technical problems and pump interfering with physical activity. In another large study specifically aimed at insulin pump treatment termination in children, the main reasons were the pump interfering with physical activity and mild body weight gain in the course of insulin pump treatment. Owing to the fact that the largest group of patients to whom the pump was withdrawn were again girls aged 10-15 years, rather esthetic nature of the reasons can be assumed.

When we dealt with the development of the individual variables in course of the follow-up, we found several statistically insignificant trends apart from the abovementioned results. The most apparent one is the mild decrease in glycosylated hemoglobin after insulin pump termination. This trend was present in evaluation of the whole group of patients as well as in individual subgroups that were assessed. We explain this by the well acknowledged fact that any change in insulin therapy regimen in most diabetic patients leads to at least a transient improvement in glycemic control, probably due to certain stress and more diligent self-monitoring. The only group of patients, where this trend could not be observed, was the one, where the insulin pump was withdrawn at the patients' own request. We believe that it may have been caused by a certain relief from stress, which the insulin pump probably meant for the patient and conversely loosening of the regimen and self-monitoring. Certain limitation, which is indirectly related to this, may be the fact that we do not know the exact number of patients, where the insulin pump was terminated by the physician, but the patient himself wanted to keep it. This information is impossible to extract from the database. Assuming our hypothesis about the stress imposed by an "unwanted" insulin pump is true, than this fact could have influenced results in the group of patients, where the pump was suspended by a physician.

\section{Conclusion}

In our study, we were not able to demonstrate any impact of insulin pump treatment termination on the further development of glycemic control of the patients. However, since this is a retrospective study, we cannot assume that our results are decisive. Probably if planed prospectively with insulin pump termination and restart after several months in the same individual may give more information. In our study we have relatively small sample size (because of high number of excluded cases with the lack of data to evaluace), quite a large number of comparisons and multiple timepoints. A larger amount of data is needed to reach more power and statistical validity for our claims (we would like to make the update of data after few years). We also remember there are many confounders that may affect the results of the study, such as age (in our study quite large spread of age, interquartil range $32.25 ; 63$ ), BMI (connected with different need of insulin per kilo, also differences between body mass of muscles and fat), history of diabetes (mean diabetes duration at time of insulin pump termination was 18.4 years, $\mathrm{SD} \pm 9.5$, from our experience we also know that in some patients with a long duration of diabetes, there is a tendency towards lability of diabetes). Another factor that may affect the results of treatment after CSII termination is drug therapy. Instead of one type of insulin (human insulins used in CSII - insulin lispro or isulin aspart), suddenly more insulin types were used in multiple daily injections after CSII termination (human insulins, insulin analogs, insulins contained in premixed preparations), in some patients there were also changes in peroral antidiabetic drugs. In our Diabetes Center we always proceed individually and in some cases it is desirable to leave the pump to the patient in spite of slightly impaired glycemic control (e.g. when the pump treatment reduces the number of severe hypoglycemias or is effective in controlling the dawn phenomenon).

\section{References}

1. Pickup J, Keen $\mathrm{H}$ (2002) Continuous subcutaneous insulin infusion at 25 years: evidence base for the expanding use of insulin pump therapy in type 1 diabetes. Diabetes Care 25: 593-598.

2. Donaghue KC, Chiarelli F, Trotta D, Allgrove J, Dahl-Jorgensen K (2009) Microvascular and macrovascular complications associated with diabetes in children and adolescents. Pediatr Diabetes 10: 195-203.

3. Marcovecchio ML, Tossavainen PH, Dunger DB (2010) Prevention and treatment of microvascular disease in childhood type 1 diabetes. $\mathrm{Br}$ Med Bull 94: $145-164$.

4. [No authors listed] (1993) The effect of intensive treatment of diabetes on the development and progression of long-term complications in insulin-dependent diabetes mellitus. The Diabetes Control and Complications Trial Research Group. N Engl J Med 329: 977-986.

5. Pickup J, Mattock M, Kerry A (2002) Glycaemic control with continuous subcutaneous insulin infusion compared with intensive insulin injection in patients with type 1 diabetes: metaanalysis of randomised controlled trials. BMJ 324: 1-6. 
Citation: Cesak V, Cesakova H, Brozova J, Jankovec Z, Rusavy Z, et al. (2015) Insulin Pump Termination in Adult Patients. J Diabetes Metab 6: 606. doi:10.4172/2155-6156.1000606

6. Weissberg-Benchell J, Antisdel-Lomaglio J, Seshadri R (2003) Insulin pump therapy: a meta-analysis. Diabetes Care 26: 1079-1087.

7. Laing SP, Swerdlow AJ, Slater SD, Burden AC, Morris A, et al. (2003) Mortality from heart disease in a cohort of 23,000 patients with insulin-treated diabetes. Diabetologia 46: 760-765

8. Holman RR, Paul SK, Bethel MA, Matthews DR, Neil HA (2008) 10-year followup of intensive glucose control in type 2 diabetes. N Engl J Med 359: 1577 1589.

9. Nathan DM, Cleary PA, Backlund JY, Genuth SM, Lachin JM, et al. (2005) Intensive diabetes treatment and cardiovascular disease in patients with type 1 diabetes. N Engl J Med 353: 2643-2653

10. Pickup JC (2013) The evidence base for diabetes technology: appropriate and inappropriate meta-analysis. J Diabetes Sci Technol 7: 1567-1574.

11. Yeh HC, Brown TT, Maruthur N, Ranasinghe P, Berger Z, et al. (2012) Comparative effectiveness and safety of methods of insulin delivery and glucose monitoring for diabetes mellitus: a systematic review and metaanalysis. Ann Intern Med 157: 336-347.

12. Charles ME, Sadri H, Minshall ME, Tunis SL (2009) Health economic comparison between continuous subcutaneous insulin infusion and multiple daily injections of insulin for the treatment of adult type 1 diabetes in Canada. Clin Ther 31: 657-67.

13. Cohen N, Minshall ME, Sharon-Nash L, Zakrzewska K, Valentine WJ, et al. (2007) Continuous subcutaneous insulin infusion versus multiple daily injections of insulin: economic comparison in adult and adolescent type 1 diabetes mellitus in Australia. Pharmacoeconomics 25: 881-97.

14. Pickup JC (2012) Insulin-pump therapy for type 1 diabetes mellitus. N Engl J Med 366: 1616-1624.

15. Nørgaard K, Scaramuzza A, Bratina N, Lalić NM, Jarosz-Chobot P, et al. (2013) Routine sensor-augmented pump therapy in type 1 diabetes: the INTERPRET study. Diabetes Technol Ther 15: 273-280.
16. Kamble S, Schulman KA, Reed SD (2012) Cost-effectiveness of sensoraugmented pump therapy in adults with type 1 diabetes in the United States. Value Health 15: 632-638.

17. Richardson T, Kerr D (2003) Skin-related complications of insulin therapy: epidemiology and emerging management strategies. Am J Clin Dermatol 4 661-667.

18. Mecklenburg RS, Benson EA, Benson JW Jr, Fredlund PN, Guinn T, et al (1984) Acute complications associated with insulin infusion pump therapy. Report of experience with 161 patients. JAMA 252: 3265-3269.

19. Guinn TS, Bailey GJ, Mecklenburg RS (1988) Factors related to discontinuation of continuous subcutaneous insulin-infusion therapy. Diabetes Care 11: 46-51.

20. Chantelau E, Spraul M, Muhlhauser I, Gause R, Berger M (1989) Long-term safety, efficacy and side effects of continuous subcutaneous insulin infusion treatment for type 1 (insulin-dependent) diabetes mellitus: a one centre experience. Diabetologia 32: 421-426.

21. Lenhard MJ, Reeves GD (2001) Continuous subcutaneous insulin infusion: a comprehensive review of insulin pump therapy. Arch Intern Med 161: 22932300.

22. Knight G (2001) Risks with continuous subcutaneous insulin infusion can be serious. BMJ 323: 693-694.

23. Hanas R, Ludvigsson $\mathrm{J}$ (2006) Hypoglycemia and ketoacidosis with insulin pump therapy in children and adolescents. Pediatr Diabetes 7: 32-38.

24. de Vries L, Grushka Y, Lebenthal Y, Shalitin S, Phillip M (2011) Factors associated with increased risk of insulin pump discontinuation in pediatric patients with type 1 diabetes. Pediatr Diabetes 12: 506-512.

25. Hofer SE, Heidtmann B, Raile K, Fröhlich-Reiterer E, Lilienthal E, et al. (2010) Discontinuation of insulin pump treatment in children, adolescents, and young adults. A multicenter analysis based on the DPV database in Germany and Austria. Pediatr Diabetes 11: 116-121 